\title{
THE EFFECT OF AIR POLLUTION ON THE RESPIRATORY SYSTEM IN PRESCHOOL CHILDREN WITH CONTRIBUTION OF URBAN HEAT ISLANDS AND GEOGRAPHIC DATA - THE AIM OF THE STUDY AND METHODOLOGICAL ASSUMPTIONS
}

\section{MONIKA BOBROWSKA-KORZENIOWSKA ${ }^{1}$, JOANNA JERZYŃSKA ${ }^{1}$, KINGA POLAŃSKA ${ }^{2}$, DOROTA KALETA ${ }^{2}$, IWONA STELMACH ${ }^{3}$, AGATA KUNERT ${ }^{4}$, and WŁODZIMIERZ STELMACH ${ }^{4}$}

${ }^{1}$ Medical University of Lodz, Łódź, Poland Copernicus Memorial Hospital in Łódź, Korczak Pediatric Center, Department of Pediatrics and Allergy

${ }^{2}$ Medical University of Lodz, Łódź, Poland

Department of Hygiene and Epidemiology

${ }^{3}$ Poddębice Health Center, Poddębice, Poland

${ }^{4}$ Medical University of Lodz, Łódź, Poland

Department of Social and Preventive Medicine

\begin{abstract}
It has been proven that outdoor and indoor air pollutants can cause adverse health effects and are able to promote the onset of atopic diseases. The current manuscript is focused on methodological issues. The aim of the study is to determine the effect of air pollution, urban environment, and urban heat islands (UHIs) on the occurrence of respiratory diseases including allergic rhinitis, asthma and wheezing in preschool children. The study group consists of 276 five-year-old children attending randomly selected kindergartens in the urban and rural areas of the Lódź Voivodeship. The questionnaire including data on the child's state of health and socio-economic data will be filled by the caregivers. The children will undergo skin prick testing and the measurement of volatile organic compounds in exhaled breath. The key components of air pollution - particulate matter (PM) will be measured by personal meters. The PM sampling planned in the study will take $12 \mathrm{~h}$ for $\mathrm{PM}_{25}$ and for PM alike. Data on the level of outdoor air pollution will be collected based on the results obtained from air monitoring stations. The impact of air pollution, UHIs and the environment on the respiratory system and the presence of allergies in children, including chronic respiratory diseases, will be assessed. The project results will provide a scientific basis for the development of preventive programs in the population of children in the Lódź Voivodeship, adapted to the real health needs of society. Int J Occup Med Environ Health. 2021;34(4):453-60
\end{abstract}

Key words:

children, air pollution, allergy, PM, VOC, respiratory system

Funding: this study was supported by the National Science Center (grant No. 2017/25/B/NZ7/00161).

Received: April 30, 2020. Accepted: October 27, 2020.

Corresponding author: Joanna Jerzyńska, Medical University of Lodz, Copernicus Memorial Hospital in Lodz, Korczak Pediatric Center, Department of Pediatrics and Allergy, Piłsudskiego 71, 90-320 Łódź, Poland (e-mail: joanna.jerzynska@umed.lodz.pl). 


\section{INTRODUCTION}

The prevalence of allergic diseases over the past few decades has increased rapidly, especially in children and young adults [1]. The dynamics of this occurrence indicates that it is the effect of changes in the environment rather than the influence of genetic factors [2]. It has been proven that air pollutants, both outdoor and indoor, can cause health problems and are able to promote the onset of atopic diseases [2,3].

The World Health Organization (WHO) reported that global air pollution had risen by $8 \%$ in 2008-2013 [4]. The key components of environmental air pollution include particulate matter (PM) concentration, carbon monoxide, nitrogen oxides, benzene and environmental tobacco smoke. According to WHO, 92\% of the world's population is exposed to excessive concentrations of PM with a diameter of $<2.5 \mu \mathrm{m}\left(\mathrm{PM}_{2.5}\right)$ referring to WHO's Ambient Air Quality Guidelines as regards the annual mean values [4].

Cohort studies have demonstrated that exposure to increased PM levels (especially $\mathrm{PM}_{2.5}$ ) has significant consequences for lung function [5-8], and children seem to be especially susceptible to the damage caused by air pollution. Outdoor $\mathrm{PM}_{10}$ can increase the risk of childhood asthma, wheezing, rhinitis and eczema among preschool children [9]. Exposure to PM might result in increased pulmonary inflammation and respiratory symptoms aggravation due to oxidative stress and, subsequently, airway hyper-responsiveness and remodeling with the participation of allergic sensitization [10]. Some data indicate that infants exposed to higher levels of pollutants and sensitized to aeroallergens have a much higher risk of asthma development compared to non-sensitized peers [11]. Fine PM can also increase the need of rescue medication in asthmatic children [12]. However, some discrepancies regarding the contribution of pollutant exposure to asthma development still exist [13], and this topic requires further examination.
There is clear evidence that asthma is the most common respiratory chronic disease in children, often characterized by underlying inflammation [14]. In order to improve the understanding of the pathogenesis of asthma, there is a need for less invasive methods than bronchoscopy in combination with bronchoalveolar lavage (BAL) to measure airway inflammation in children [15,16]. The analysis of exhaled volatile organic compounds (VOCs) in exhaled breath can enable an assessment of airway inflammation [16-18]. According to recent data, the evaluation of exhaled VOC profiles may help to non-invasively diagnose [19] and monitor asthma [20-22]. Dutch investigators have suggested that analyzing VOCs in exhaled breath using gas chromatography - mass spectrometry (GC-MS) could enable differentiating between asthmatic and non-asthmatic children [23]. An assessment of VOC profiles could significantly improve the diagnostic process of asthma, especially in preschoolage children with preclinical asthma, and separate them from patients with recurrent but transient wheezing [24,25], but the clear statement is needed at the early stage.

The urban heat island (UHI) is a well-studied phenomenon, whereby metropolitan areas experience elevated temperatures, compared to their surrounding suburban and rural areas, due to human activities [26]. In fact, the UHI significantly affects the health of people living under its influence [26]. Urbanized UHI areas are characterized by elevated ambient temperatures, increased concentrations of carbon monoxide, carbon dioxide, sulphur dioxide, nitrogen dioxide, as well as increased concentrations of PM and ozone causing an increase in allergen production. Those factors can alter plant physiology and increase allergen production [27].

The present study was designed to be conducted on a group of preschool children from the Łódź Voivodeship. The aim of the study is to determine the effect of air pollution, urban environment, and UHIs on the occurrence of respiratory diseases including allergic rhinitis, asthma and wheezing in preschool children. 
The current manuscript is focused on methodological issues.

\section{Objectives}

The research tasks are listed below:

- an assessment of the child's exposure to air pollution by PM sampling using personal meters;

- a differential diagnosis of bronchial asthma and expiratory wheezing by determining VOCs in exhaled breath;

- an assessment of the incidence of allergic rhinitis, bronchial asthma and expiratory wheezing in the population of preschool children, using a questionnaire;

- an assessment of the impact of air pollution, UHIs and the environment (the terrain and demographic data from a given region of residence); the microbiome of the upper respiratory tract on the respiratory system; the presence of allergies in children, including chronic respiratory diseases, and medications used; the number of respiratory infections; and the number of hospitalizations.

\section{METHODS}

\section{Population}

The study group consists of 5-year-old children attending kindergartens in the urban and rural areas of the city of Łódź and the Łódź Voivodeship, taking into account areas with low, medium and high levels of dust pollution and sulphur dioxide ( 2 kindergartens in each area). In each of these areas, 2 kindergartens in the city and 2 kindergartens in the Voivodeship (a total of 12 kindergartens) will be chosen randomly. Patient recruitment will be conducted until the assumed number is reached in each of the groups ( 23 children in the kindergarten), i.e., up to 138 people attending kindergartens in the city and up to 138 people attending kindergartens in the Voivodeship.

Headmasters of the randomly selected kindergartens will be asked to give their permission to conduct the study in the facilities. Then, the research team will organize meetings with parents/caregivers in these kindergartens, during which they will explain the aim and procedures of the study, collect consent for the children from their parents/caregivers to participate in the study, and the questionnaires to be filled by the parents/caregivers. After that, a medical doctor and a researcher from the Łódź Regional Park of Science and Technology will visit each kindergarten. This visit will cover: skin prick testing (SPT), the measurement of VOCs in exhaled breath, an assessment of the microbiome of the upper respiratory tract, as well as the handover of a backpack containing personal meters, or more specifically GilAir Plus Basic personal aspirators, which will measure air pollution. After $24 \mathrm{~h}$, the backpacks with the equipment will be gathered by the study staff.

The study was approved by the Ethics Committee of the Medical University of Lodz (decision No. RNN/390/17/KE). The participants have the right to withdraw their consent for further participation in the study at any time. They will be informed that all the obtained data are used only for research purposes.

\section{Questionnaire}

The questionnaire addressed to the parents/caregivers of the child will include data on the child's state of health, exposure to air pollution, and socio-economic data. The survey will be developed on the basis of the International Study of Asthma and Allergies in Childhood and the European Community Respiratory Health Survey. The questionnaire will be expanded with additional issues such as: child nutrition, natural feeding, children's physical activity and living conditions. The second part of the questionnaire contains questions regarding the child's health including information about any doctor-diagnosed allergy and asthma, the severity and frequency of diseases, medications taken and hospitalizations [28]. 


\section{Environment assessment}

The measurement of air pollution using GilAir Plus Basic (Clearwater, FL, USA) personal aspirators is planned. The GilAir Plus Basic personal sampling pump measuring dust, gases and vapors has the capability of generating and controlling flow over the range of $20-5000 \mathrm{cc} / \mathrm{min}$ in 2 flow ranges, 20-449 $\mathrm{cc} / \mathrm{min}$, and 450-5000 $\mathrm{cc} / \mathrm{min}$, which are selectable using a 2-millimeters or 5/64-inch hex key (provided with the pump). The actual flow is measured and controlled by the pump's internal processor. Flow control is provided directly in the constant flow mode. Pressure control is provided in the constant pressure control mode, which controls flow indirectly. During a sampling event, the flow rate is displayed in the constant flow mode and back pressure is displayed in the constant pressure mode. The PM sampling planned in the study will take $12 \mathrm{~h}$ (720 min) for $\mathrm{PM}_{2.5}$ and $\mathrm{PM}_{10}$ alike. The air flow rate used for sampling will be $3.5 \mathrm{l} / \mathrm{min}$.

The collected dust samples will be analyzed in the Aerosol Laboratory of the Nofer Institute of Occupational Medicine in Łódź. The filters will be placed in containers with individual identifiers, and then weighed before and after collecting dust samples to determine the dust concentration which is calculated as the ratio of the mass of dust retained in the filter to the volume of the air passed through the filter. Prior to weighing, clean filters will be placed in a silica gel desiccator and conditioned for at least $20 \mathrm{~h}$, and then weighed on the same weight. A Sartorius R $180 \mathrm{D}$ analytical balance allowing weighing with a resolution of $0.01 \mathrm{mg}$, having a calibration certificate issued by an accredited calibration laboratory, will be used. Each time before weighing, the correctness of balance indications will be checked by means of a mass standard having a calibration certificate issued by the Central Office of Measures, Poland.

Data on the level of outdoor air pollution will be collected based on the results from air monitoring stations. The Geographic Information System will be used to link the information about the place of residence and the attended kindergarten to the data from local air monitoring stations.

The analysis of the phenomenon of UHIs based on the spatial structure of the Lódź Voivodeship, taking into account the children's residence, spatial data, demographic data and respiratory diseases in children, is planned.

\section{Skin prick testing}

Skin prick testing will be performed with the most common inhalant allergens: Dermatophagoides farinae, Dermatophagoides pteronyssinus, Alternaria, Cladosporium, cat dander, dog dander, mixed grass pollen, rye, birch, hazel, ribwort, alder and mugwort, together with a positive (histamine chloride $10 \mathrm{mg} / \mathrm{ml}$ ) and negative (glycerol) control (extracts from HAL Allergy, Leiden Bio Science Park, the Netherlands). A positive SPT reaction is defined as a mean weal diameter $>3 \mathrm{~mm}$ in excess of the negative control, according to the European Academy of Allergy and Clinical Immunology [29,30].

\section{Assessment of the microbiome \\ of the upper respiratory tract}

Microbiota composition will be assessed in a nasopharyngeal swab. The analysis will be done using the next generation sequencing technique of the 16-second episode at the Biobank of the University of Lodz.

\section{Assessment of inflammation in respiratory tract}

The measurement of VOCs in exhaled breath in each child, using the GC-MS method in a laboratory in the Łódź Regional Park of Science and Technology will be performed. Breath samples will be collected in Tedlar ${ }^{\circledR}$ bags and then transferred to the Tenax TA filled tubes (GERSTEL GmbH \& Co. KG, Mülheim an der Ruhr, Germany) using a peristaltic pump. After that, the volatiles will be desorbed in the thermal desorption unit (GERSTEL GmbH \& Co. KG, Mülheim an der Ruhr, Germany). The ther- 
mal desorption conditions will be as follows: a temperature program of $20-270^{\circ} \mathrm{C}(5 \mathrm{~min})$ at $60^{\circ} \mathrm{C} / \mathrm{min}$, helium as a carrier gas, a flow of $50 \mathrm{ml} / \mathrm{min}$ during desorption, and the splitless mode.

The Cooled Injection System CIS4 (GERSTEL GmbH \& Co. KG, Mülheim an der Ruhr, Germany) injector conditions will be as follows: the spitless mode, a liner packed with Tenax TA, and a temperature program of $-30^{\circ} \mathrm{C}$ during thermal desorption, then increased to $280^{\circ} \mathrm{C}$ at a rate of $6^{\circ} \mathrm{C} / \mathrm{s}$.

The chromatographic conditions will be as follows: a gas chromatograph (Agilent 7890A, Agilent Technologies, Santa Clara, CA, USA) equipped with BPX-5 capillary column (a length of $30 \mathrm{~m}$, an internal diameter of $0.25 \mathrm{~mm}$, a film thickness of $0.25 \mu \mathrm{m}$, Trajan Scientific Australia Pty Ltd, Ringwood, Victoria, Australia), the GC oven temperature initially held at $40^{\circ} \mathrm{C}$ for $5 \mathrm{~min}$, and then increased to $100^{\circ} \mathrm{C}$ at a rate of $3^{\circ} \mathrm{C} / \mathrm{min}$, and then further increased to $250^{\circ} \mathrm{C}$ at a rate of $10^{\circ} \mathrm{C} / \mathrm{min}$, helium as a carrier gas at a flow of $0.8 \mathrm{ml} / \mathrm{min}$, and a transfer line temperature of $280^{\circ} \mathrm{C}$.

Mass spectra will be collected using a Pegasus 4D TimeOf-Flight Mass Spectrometer (Leco Corp., St. Joseph, MI, USA). The settings of the spectrometer are as follows: an ion source temperature of $200^{\circ} \mathrm{C}$, ionization energy of $70 \mathrm{eV}$, and a scan range of 33-450 atomic mass units at $50 \mathrm{spectra} / \mathrm{s}$. The obtained mass spectra will be compared with NIST/EPA/NIH and the Wiley Registry of Mass Spectral Data mass spectral libraries.

The obtained data will be processed using the Statistical Compare feature implemented in the ChromaTof software (Leco Corp., St. Joseph, MI, USA).

\section{Power calculation and sample size}

The sample size was calculated as a function of the type I error level and the magnitude of the effect using the z-test for 2 independent ratios using the statistical package Statistica version 13. The minimum sample size to reach the stated objectives of the study is 276 children in total (138 children in each group - living in the UHI area and in the Voivodeship).

\section{Statistical analysis}

Descriptive analyses encompass both numerical and categorical variables. The numerical traits are depicted by using arithmetic means (or geometric means, or median values, if applicable), standard deviation, and standard error values along with corresponding $95 \%$ confidence limits. The categorical traits are described using absolute numbers and percentages.

The concentrations of $\mathrm{PM}_{10}$ and $\mathrm{PM}_{2.5}$, to be measured, in fact, over a 12-hour period, will be averaged on the day of taking other relevant measurements. A moving average will then be used in order to qualify all these measurements. Referring to the study design, actually based on recruiting subjects from different locations, i.e., from several kindergartens, both from rural and urban areas, multilevel modeling (MLM) will be carried out. In fact, MLM will be a key concept when taking into account the subsequent statistical test of significance. Going further into the details, multifactor linear, multifactor binary logistic, and multifactor ordinal logistic regression models will be fitted, depending on the nature of the dependent variable (i.e., respectively, a numerical, dichotomous, or ordinal one). All the said regression models will be controlled for the study participants' demographic characteristics, domestic conditions, family history, and atmospheric/environmental factors if applicable.

The Pearson product-moment correlation coefficients and Spearman's rank correlation coefficients will also be calculated in order to depict some interesting relationships between the variables.

A level of $p<0.05$ will be deemed statistically significant.

\section{RESULTS}

The project is innovative because so far no similar research has been carried out in Poland. 
Its results will reveal the occurrence of allergic rhinitis, bronchial asthma and expiratory wheezing in the population of preschool children, and the impact of outdoor and indoor air pollution, UHIs and the microbiome of the upper respiratory tract on the respiratory system as well as on the presence of allergies. Finally, determining VOCs in exhaled breath will help to differentiate between bronchial asthma and expiratory wheezing in the study participants.

\section{CONCLUSIONS}

There is no data on which the development of preventive programs in the pediatric population may be based in Poland. The project results will, therefore, provide a scientific basis for the development of preventive programs in the children population in the Lódź Voivodeship, adapted to the real health needs of society. Such programs are necessary since approximately $40 \%$ of children in Poland suffer from allergies, and children aged 6-7 who live in cities have a 5-fold increase in the risk of allergies compared to children of the same age group living in rural areas [31].

\section{REFERENCES}

1. Pawankar R. Allergic diseases and asthma: a global public health concern and a call to action. World Allergy Organ J. 2014;7(1):12, https://doi.org/10.1186/1939-4551-7-12.

2. Burbank AJ, Sood AK, Kesic MJ, Peden DB, Hernandez ML. Environmental determinants of allergy and asthma in early life. J Allergy Clin Immunol. 2017;140(1):1-12, https://doi.org/ 10.1016/j.jaci.2017.05.010.

3. D’Amato G, Rottem M, Dahl R, Blaiss M, Ridolo E, Cecchi $\mathrm{L}$, et al. Climate change, migration, and allergic respiratory diseases: an update for the allergist. World Allergy Organ J. 2011;4(7):120-5, https://doi.org/10.1097/WOX.0b013e $3182260 a 57$.

4. World Health Organization [Internet]. Geneva: The Organization; 2020 [cited 2020 Apr 20]. Available from https://www. who.int/airpollution/ambient/en.
5. Gehring U, Gruzieva O, Agius RM, Beelen R, Custovic A, Cyrys J, et al. Air pollution exposure and lung function in children: the ESCAPE project. Environ Health Perspect. 2013;121(11-12):1357-64, https://doi.org/10.1289/ehp.130 6770.

6. Gehring U, Wijga AH, Hoek G, Bellander T, Berdel D, Bruske I, et al. Exposure to air pollution and development of asthma and rhinoconjunctivitis throughout childhood and adolescence: a population-based birth cohort study. Lancet Respir Med. 2015;3(12):933-42, https://doi.org/10.1016/ S2213-2600(15)00426-9.

7. Bowatte G, Lodge C, Lowe AJ, Erbas B, Perret J, Abramson MJ, et al. The influence of childhood traffic-related air pollution exposure on asthma, allergy and sensitization: a systematic review and a meta-analysis of birth cohort studies. Allergy. 2015;70(3):245-56, https://doi.org/10.1111/all.12561.

8. Rancière F, Bougas N, Viola M, Momas I. Early Exposure to Traffic-Related Air Pollution, Respiratory Symptoms at 4 Years of Age, and Potential Effect Modification by Parental Allergy, Stressful Family Events, and Sex: A Prospective Follow-up Study of the PARIS Birth Cohort. Environ Health Perspect. 2017;125(4):737-45, https://doi.org/10.1289/EHP239. 9. Norbäck D, Lu C, Zhang Y, Li B, Zhao Z, Huang C, et al. Sources of indoor particulate matter (PM) and outdoor air pollution in China in relation to asthma, wheeze, rhinitis and eczema among pre-school children: Synergistic effects between antibiotics use and $\mathrm{PM}_{10}$ and second hand smoke. Environ Int. 2019;125:252-60, https://doi.org/10.1016/j.envint. 2019.01.036.

10. Stanek LW, Brown JS, Stanek J, Gift J, Costa DL. Air pollution toxicology - a brief review of the role of the science in shaping the current understanding of air pollution health risks. Toxicol Sci. 2011;120 Suppl 1:S8-27, https://doi.org/10. 1093/toxsci/kfq367.

11. Brandt EB, Biagini Myers JM, Acciani TH, Ryan PH, Sivaprasad U, Ruff B, et al. Exposure to allergen and diesel exhaust particles potentiates secondary allergen-specific memory responses, promoting asthma susceptibility. J Allergy 
Clin Immunol. 2015;136(2):295-303.e7, https://doi.org/10. 1016/j.jaci.2014.11.043.

12. Mc Cormack MC, Breysse PN, Matsui EC, Hansel NN, Williams D, Curtin-Brosnan, J, et al. In-home particle concentrations and childhood asthma morbidity. Environ Health Perspect. 2009;117(2):294-8, https://doi.org/10.1289/ ehp.11770.

13. Molter A, Simpson A, Berdel D, Brunekreef B, Custovic A, Cyrys J, et al. A multicentre study of air pollution exposure and childhood asthma prevalence: the ESCAPE project. Eur Respir J. 2015;45(3):610-24, https://doi.org/10.1183/ 09031936.00083614.

14. Licari A, Castagnoli R, Brambilla I, Marseglia A, Tosca MA, Marseglia GL, et al. Asthma Endotyping and Biomarkers in Childhood Asthma. Pediatr Allergy Immunol Pulmonol. 2018;31(2):44-55, https://doi.org/10.1089/ped.2018.0886.

15. Vijverberg SJ, Hilvering B, Raaijmakers JA, Lammers JW, Maitland-van der Zee AH, Koenderman L. Clinical utility of asthma biomarkers: from bench to bedside. Biologics. 2013;7:199-210, https://doi.org/10.2147/BTT.S29976.

16. Tenero L, Zaffanello M, Piazza M, Piacentini G. Measuring Airway Inflammation in Asthmatic Children. Front Pediatr. 2018;6:196, https://doi.org/10.3389/fped.2018.00196.

17. Smolinska A, Klaassen EM, Dallinga JW, van de Kant KD, Jobsis Q, Moonen EJ, et al. Profiling of volatile organic compounds in exhaled breath as a strategy to find early predictive signatures of asthma in children [published correction appears in PLoS One. 2014;9(8):e105447]. PLoS One. 2014;9(4): e95668, https://doi.org/10.1371/journal.pone.0095668.

18. Ferraro V, Carraro S, Bozzetto S, Zanconato S, Baraldi E. Exhaled biomarkers in childhood asthma: old and new approaches. Asthma Res Pract. 2018;4:9, https://doi. org/10.1186/s40733-018-0045-6.

19. Neerincx AH, Vijverberg SJH, Bos LDJ, Brinkman P, van der Schee MP, de Vries R, et al. Breathomics from exhaled volatile organic compounds in pediatric asthma. Pediatr Pulmonol. 2017;52(12):1616-27, https://doi.org/10.1002/ppul. 23785 .
20. Brinkman P, van de Pol MA, Gerritsen MG, Bos LD, Dekker T, Smids BS, et al. Exhaled breath profiles in the monitoring of loss of control and clinical recovery in asthma. Clin Exp Allergy. 2017;47(9):1159-69, https://doi.org/10.1111/ cea.12965.

21. Robroeks CM, van Berkel JJ, Jöbsis Q, van Schooten F-J, Dallinga JW, Wouters EF, et al. Exhaled volatile organic compounds predict exacerbations of childhood asthma in a 1-year prospective study. Eur Respir J. 2013;42(1):98-106, https:// doi.org/10.1183/09031936.00010712.

22. Van Vliet D, Smolinska A, Jöbsis Q, Rosias PPR, Muris JWM, Dallinga JW, et al. Association between exhaled inflammatory markers and asthma control in children.J Breath Res. 2016;10(1):016014, https://doi.org/10.1088/1752-7155/10/ $1 / 016014$.

23. Dallinga JW, Robroeks CMHHT, van Berkel JJBN, Moonen EJC, Godschalk RWL, Jöbsis Q, et al. Volatile organic compounds in exhaled breath as a diagnostic tool for asthma in children. Clin Exp Allergy. 2010;40(1):68-76, https://doi.org/10.1111/j.1365-2222.2009.03343.X.

24. Van Vliet D, Smolinska A, Jöbsis Q, Rosias P, Muris J, Dallinga J, et al. Can exhaled volatile organic compounds predict asthma exacerbations in children? J Breath Res. 2017;11(1): 016016, https://doi.org/10.1088/1752-7163/aa5a8b.

25. Klaassen EMM, van de Kant KDG, Jöbsis Q, van Schayck OCP, Smolinska A, Dallinga JW, et al. Exhaled biomarkers and gene expression at preschool age improve asthma prediction at 6 years of age. Am J Respir Crit Care Med. 2015;191(2): 201-7, https://doi.org/10.1164/rccm.201408-1537OC.

26. Heaviside C, Macintyre H, Vardoulakis S. The Urban Heat Island: Implications for Health in a Changing Environment. Curr Environ Health Rep. 2017;4(3):296-305, https://doi. org/10.1007/s40572-017-0150-3.

27. Blazejczyk K, Kuchcik M, Dudek W, Kręcisz B, Błażejczyk A, Milewski P, et al. Urban Heat Island and Bioclimatic Comfort in Warsaw. In: Musco F, editor. Forecasting Models for Urban Warming in Climate Change. Cham: Springer Nature Switzerland AG; 2016. p. 305-21. 
28. The International Study of Asthma and Allergies in Childhood [Internet]. Auckland: The University of Auckland; 2013 [cited 2020 Apr 20]. Available from: http://isaac.auckland.ac.nz.

29. Burbach GJ, Heinzerling LM, Edenharter G, Bachert C, Bindslev-Jensen C, Bonini S, et al. GA(2)LEN skin test study II: clinical relevance of inhalant allergen sensitizations in Europe. Allergy. 2009;64(10):1507-15, https://doi.org/10. 1111/j.1398-9995.2009.02089.x.
30. Heinzerling L, Mari A, Bergmann K. Bresciani M, Burbach G, Darsow U, et al. The skin prick test - European standards. Clin Transl Allergy. 2013;3(1):3, https://doi.org/10. 1186/2045-7022-3-3.

31. Stróżek J, Samoliński BK, Kłak A, Gawińska-Drużba E, Izdebski R, Krzych-Fałta E, et al. The indirect costs of allergic diseases. Int J Occup Med Environ Health. 2019;32(3): 281-90, https://doi.org/10.13075/ijomeh.1896.01275.

This work is available in Open Access model and licensed under a Creative Commons Attribution-NonCommercial 3.0 Poland License - http://creativecommons.org/ licenses/by-nc/3.0/pl/deed.en. 